The 5th International Symposium on Robotics in Construction June 6-8, 1988 Tokyo, Japan

\author{
DEVELOPMENT OF A FULLY AUTOMATIC \\ CLEAN ROOM MEASURING SYSTEM \\ Akira Ohsakaya \\ Toda Construction Co.,Ltd. \\ Kaname 315 , Tukuba-city, \\ l baragi 300-15, Japan
}

\begin{abstract}
The more highly the performance of clean rooms are required, the more frequently and closely we must measure and analyze the environment of them, not only as built facility but also as operating facility. Fully automatic clean room measuring system" CLEAN-WATCHER" has been developed in order to automatically measure and analyze the paricle concentration, temperature, humidity, wind velocity distribution and to carry out scan test of filters attached on ceiling, at any position in down flow clean rooms without attendance of operator. This paper describes the outline of this system.
\end{abstract}

1 Introduction

With the increasing requirements for the performance of clean rooms, filter scan tests and other measuring and analyses for particle concentration, temperature, humidity, wind velocity distribution, and other environment conditions are required during normal " Operating Facility " in addition to testing at the time of "As Built Facility", in order to maintain the performance.

As the robot "CLEAN-WATCHER ( in the following called CW )" has been developed for automatic measuring and analyses of these environment conditions of the experimental clean room in our laboratory, it shall be outlined in the following.

2 Outline of the CLEAN-WATCHER

Table 1 shows a classification of the robots used by the various construction companies for clean room measuring and analysis. A large number of the robots used until now is of the traverse type. The traverse type is superior to the automated-guided-vehicle (AGV) type in regard to the positioning accuracy, but rails or a special frame for running arerequired, and the freedom of the experimental clean room in our laboratory is impaired. As the AGV type requires no fixed rails etc., the system can be developed for use not only in the experimental clean room but also for grasping of the performance of the "As Built" or "Operating" facilities in producing factories. 
Thus the basic policy of using a AGV type was decided, but various problem points are assumed for the already developed AGV type clean room measuring robots '1'. Accordingly, the following development targets were set.

(1) Free travel shall be possible on grating, and the positioning accuracy shall be within $\pm 5 \mathrm{~mm}$ for the vehicle.

(2) Sensor movement shall be possible to all points of the experimental clean room in our laboratory, and there shall be no measuring loss locations ( 150 $\mathrm{mm}$ to $3000 \mathrm{~mm}$ above the floor).

(3) A language as simple as BASIC shall be used, and unmanned mobile measuring shall be possible with batch processing.

(4) Generation and editing of teaching date shall be possible outside of the clean room.

(5) Mobile measuring with loading of various measuring instruments with an RS232C communications interface shall be possible (particle concentration, temperature, humidity, wind speed, etc.).

(6) The size shall be so that transporting to locations outside of the clean room laboratory is possible through doors of normal size, and the weight shall be light.

(7) No particles shall be emitted from the robot body to clean rooms.

(8) The robot shall be equipped with sufficient safety devices.

(9) Use for applications other than measuring (repeated testing etc. ) also shall be possible.

\section{System Composition and Functions}

The system composition is shown in Fig.1, the system control mechanism is shown in Fig.2, and the main specifications are shown in table 2.

The functions are explained in the following.

\section{(1) Vehicle}

The measuring instruments are loaded onto the rear of the vehicle for movement. The vehicle can travel freely in $X$ and $Y$ direction. The wheels have a large diameter and a large width, and for change of the travelling direction, outriggers installed at the four corners of the vehicle are used to raise the vehicle for turning of the entire drive mechanism.

In this way, the movement direction can be changed without changing the orientation of the vehicle.

(2) Manipulator

The manipulator is a vertical type with 6 joints, and complicated movements 
are possible. The manipulator movement is assumed to permit handling of semiconductor wafers, and smooth movement can be realized.

\section{(3) Snensor Holder}

The sensor holder is located at the tip of the pall installed at the tip of the manipulator, and the sensor is fixed with rubber bands. As the sensor holder uses a pendulum mechanism, the sensor always maintains the same direction even when it is moved to any point from $150 \mathrm{~mm}$ to $3000 \mathrm{~mm}$ above the floor.

\section{(4) Measuring Instrument Loading Part}

The instruments are fixed with a belt inside an acryl case. For a measuring instrument $\mathrm{AC} 100 \mathrm{~V}$, and an RS232C connector are provided.

Measuring is possible for the 4 types of particle concentration, temperature, humidity, and wind velocity, and table 3 shows an outline of presently mounted measuring instruments.

\section{(5) Camera}

As wheeles are used for travelling, with positioning by means of an encoder coupled with the motor, it is not possible to avoid position errors caused by slip between the wheels and the floor. In order to compensate for this error, a CCD camera is installed at the tip of the manipulator, the video signal from the camera is converted to a binary black-and-white signal, divided into $512 \times$ 512 picture elements, and taken into a frame memory. A bar code pattern is recognized from this picture information.

(6) Bar Code

The bar code is a pattern consisting of black and white bits, and it is applied to the floor. The picture is recognized by the CCD camera, the side position of the truck from the path $X$, the distance $\gamma$ between the bar code and the vehicle center, and angle $\theta$ between the vehicle center $l$ ine and the path are read, and the deviation is compensated automatically.

The vehicle position is compensated by bar code application at the measuring coordinate origin or an intermediate point, and the travelling accuracy is improved.

\section{(7) Operation Part}

This is formed by a personal computer. The entire CW operation can be executed from outside the clean room.

(8) Safety Measures and Devices

a) Ultrasonic Sensor

one sensor each is installed at the center of each side of the vehicle to decelerate the vehicle when a wall, a human, or any other object is detected.

b) Bumper Sensor

This sensor is arranged on the lower circumference of the vehicle and stops 
the movement of the robot on contact with an object.

c) Touch Sensor

This is installed at the pall tip in approximately the same position as the sensor holder, and the robot movement is stopped when this sensor comes into contact with an object.

d) Other Safety Measures

An emergency stop switch, a wire break detector, a motor overheat detector, and other self-diagnosis functions are provided.

(9) Cable Part

Wireless transmission of the CW operation and measuring date has been investigated, but as the power supply capacity of the built-in fan of the particle counter for measuring of the particle concentration is large, a wire method was adapted for the $C W$ developed this time.

There are two cables, one for power supply and one for signals, and the cables are paid out or reeled in automatically according to the vehicle movement.

\section{(10) Countermeasures against Particle Emittion}

Possible CW particle sources are motors, transmission system, bearing, wheels, cables, lubrication oil, cooling fan, etc. In order to prevent spreading of particles from these particle sources, the bearings are provided with magnetic fluid seals, a suction fan is installed at the bottom part of the manipulator to obtain a negative pressure for the inside, and the particles are discharged from the vehicle bottom and the rear bottom (refer tofig. 3 ).

In order to confirm the effect of these countermeasures, measuring has been executed in the experimental clean room in our laboratory ${ }^{2}$.

No particles of $0.1 \mu \mathrm{m}$ or more were detected directly below the manipulator joints and in the direct vicinity of the vehicle, except for the cable outlet.

The total discharged particles through the vehicle bottom and the cable outlet by the effect of a suction fan installed were about 300,000 particles per minute with a size of $0.1 \mu \mathrm{m}$ or more and 20,000 to 40,000 particles with a size of $0.3 \mu \mathrm{m}$ or more, which is $1 / 100$ or less of the particles emitted from a walking human clothed in clean room garments ${ }^{3}$ ).

4 Measuring by Means of the CLEAN-WATCHER

Measuring by means of $\mathrm{CW}$ is executed in the following sequence.

(1) Input of measuring items, mode, teaching date file name, etc. from the operation part (personal computer).

(2) Origin return for manipulator and vehicle.

(3) Reading of the bar code on the floor with the cco camera at the manipulator 
tip and correction of the vehicle position.

(4) Movement of the vehicle, measuring sensor positioning with the manipulator at the measuring points.

(5) Measuring with the measuring instruments.

(6) Transmission of position date and mesuring date to the personal computer.

(7) Display of measuring date and measuring points on the CRT and saving of the date onto a floppy disk.

(8) Repetition of the steps (4) to (7).

After completion of measuring, the date are analyzed, and counter indication of the distributions is possible.

For execution of scan test for HEPA filters or other filters installed in the ceilig, the vehicle is moved to under the filter, and then i near interpolation operation is executed for the manipulator.

For execution of these series of operations, the position date must be taught in advance, but when teaching has been done once, the same teaching date can be used repeatedly even for measuring of other items, so that wide improvements can be obtained in regard to work reduction for the measuring and date reliability.

\section{Conclusion}

The fully automatic clean room measuring system CLEAN-WATCHER presently operating in the experimental clean room in our laboratory has been outlined.

The CLEAN-WATCHER developed this time basically has the functions for transport of semiconductor wafers, and it is believed that investigation of the influence of particles and vibrations generated by the robot body will contribute widely to automation and robot introduction for the semiconductor indusry. Also, the successful development of a system permitting measuring at several points up to several hundred points without entry into the clean room is considered as contributing to the future development towards unmanned environment control systems for clean rooms.

\section{REFERENCES}

1) S.Kosaka and A.ohsakaya, "Development and Performance of a Fully Automatic Clean Room Measuring System ", Manuscript for the 6 th Air Cleaning and

Contamination Control Research Meeting, Japan Air Cleaning Association ,ppg7 $-102,1987$

2) S.Kosaka and A.ohsakaya, "In Regard to a Clean Room Automatic Measuring, Robot, Part2. Particle Generation Characteristics of the Robot ", Summaries of Technical papers of Annual Meeting. Architectural Institute of Japan,pp1181-1182 , 1987

3) Guidance for operation of Clean Room, Japan Air Cleaning Association, 1984 
Table l Classification of the Robots Used for Clean Room Measuring and Analysis

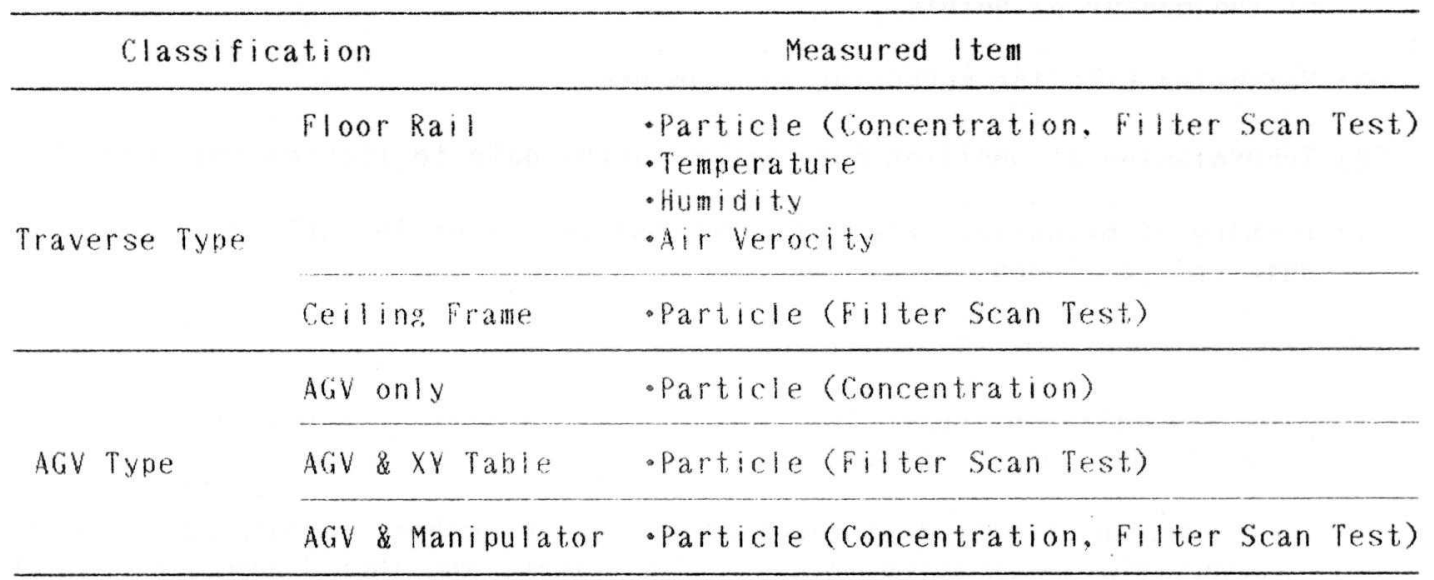

Table 2 Specifications of CLEAN-WATCHER

\begin{tabular}{|c|c|c|}
\hline & Item & Specifications \\
\hline Mechanism & $\begin{array}{l}\text {-Dimension } \\
\text { - Weight } \\
\text { - Camera } \\
\text { - Bar Code } \\
\text { - Service outlet } \\
\text {-Power Supply }\end{array}$ & 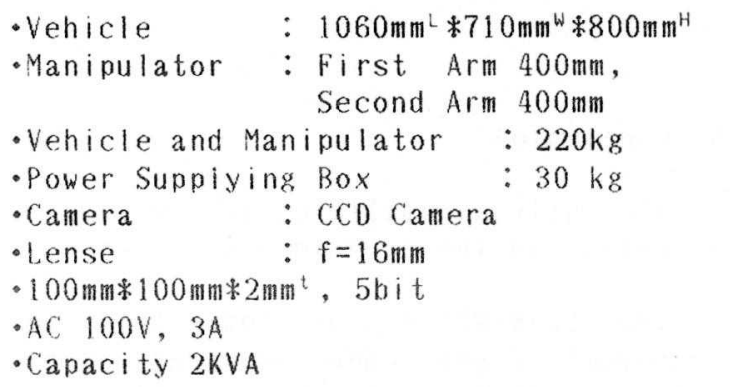 \\
\hline Function & $\begin{array}{l}\text { - Positioning Accuracy } \\
\text { - Speed } \\
\text {-Carrying Capacity } \\
\text { - Guidance System } \\
\text { - Sampling Head } \\
\text { - Communication } \\
\text { - Advancing birection } \\
\text { - Floor Type } \\
\text { - Cable Control }\end{array}$ & 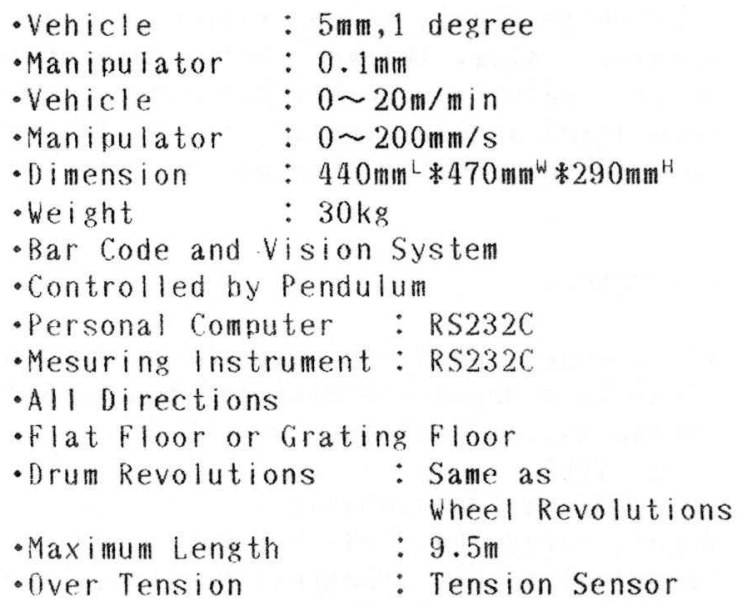 \\
\hline
\end{tabular}

\section{5㓛 绾回}


Table 3 Mesuring Instruments Mounted on CLEAN-WATCHER

\begin{tabular}{|c|c|c|c|}
\hline Measured Item & Type & Specif & fications \\
\hline Particle & $\begin{array}{l}\mathrm{R} 10 \mathrm{~N} \\
\mathrm{KC}-03\end{array}$ & $\begin{array}{l}\text { Particle Size } \\
\text { Sample Flow }\end{array}$ & $\begin{array}{l}\text { Range : } 0.3 \sim 5.0 \mu \mathrm{m} \\
: 3 \mathrm{l} / \mathrm{min}\left(0.1 \mathrm{ft}^{3} / \mathrm{min}\right)\end{array}$ \\
\hline Temperature & $\begin{array}{l}\text { RISY0 } \\
\text { DMT }-610\end{array}$ & $\begin{array}{l}\text { Sensor } \\
\text { Range } \\
\text { Accuracy }\end{array}$ & $\begin{array}{l}: \text { Crystal Probe } \\
:-50 \sim 15^{\circ} \mathrm{C} \\
: \pm 0.1^{\circ} \mathrm{C}\end{array}$ \\
\hline Humidity & $\begin{array}{l}\text { VAISALA } \\
\text { HMI }-32\end{array}$ & $\begin{array}{l}\text { Range } \\
\text { Accuracy }\end{array}$ & $\begin{array}{l}: 0 \sim 100 \% R H \\
: \pm 2 \%\end{array}$ \\
\hline Air Verocity & $\begin{array}{l}R 10 N \\
A M-10\end{array}$ & $\begin{array}{l}\text { Sensor } \\
\text { Range } \\
\text { Accuracy }\end{array}$ & $\begin{array}{l}: \text { Transistor Probe } \\
: 0.05 \sim 25 \mathrm{~m} / \mathrm{s} \\
: 0.05 \mathrm{~m} / \mathrm{s}\end{array}$ \\
\hline $\begin{array}{l}\text { Electric Current, } \\
\text { Voltage }\end{array}$ & $\begin{array}{l}\text { ETO } \\
\text { THERMODAC } 32\end{array}$ & $\begin{array}{r}18 \text { Channel Ana } \\
10 \text { Channel Pul } \\
4 \text { Channel Dig }\end{array}$ & $\begin{array}{ll}\text { log } & \text { Data } \\
\text { Ise } & \text { Data } \\
\text { gital } & \text { Data }\end{array}$ \\
\hline
\end{tabular}

< MEASURING ROOM >

< CLEAN ROOM >

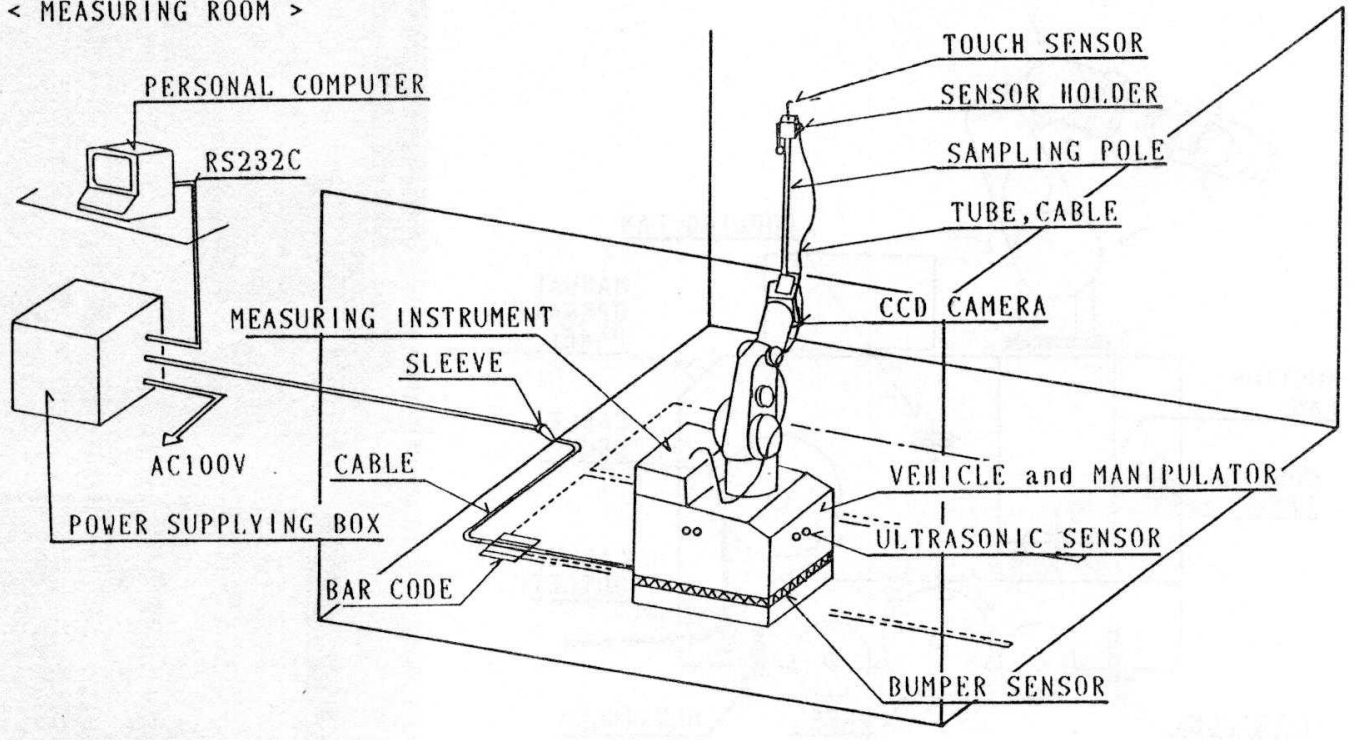

Fig. 1 System Composition of CLEAN-WATCHER 


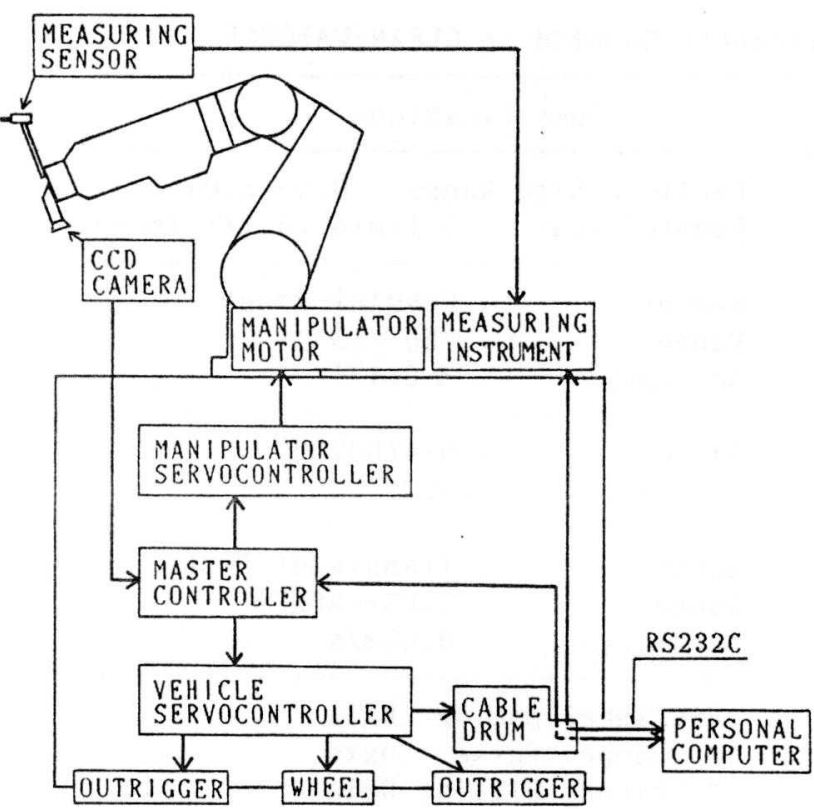

Fig.2 System Control Mechanism

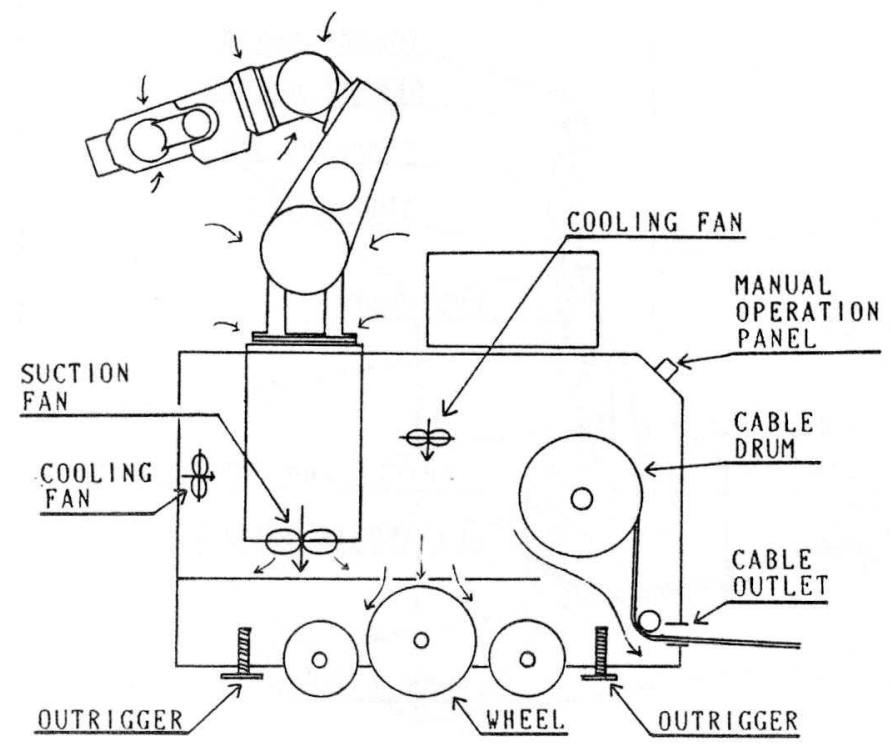

Fig. 3 Countermeasures against Particle Emittion

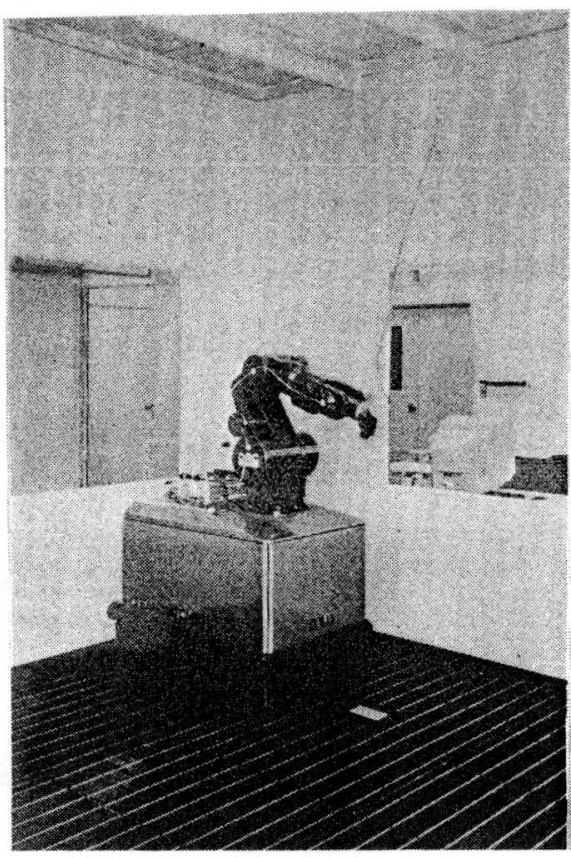

Photo.1 General View

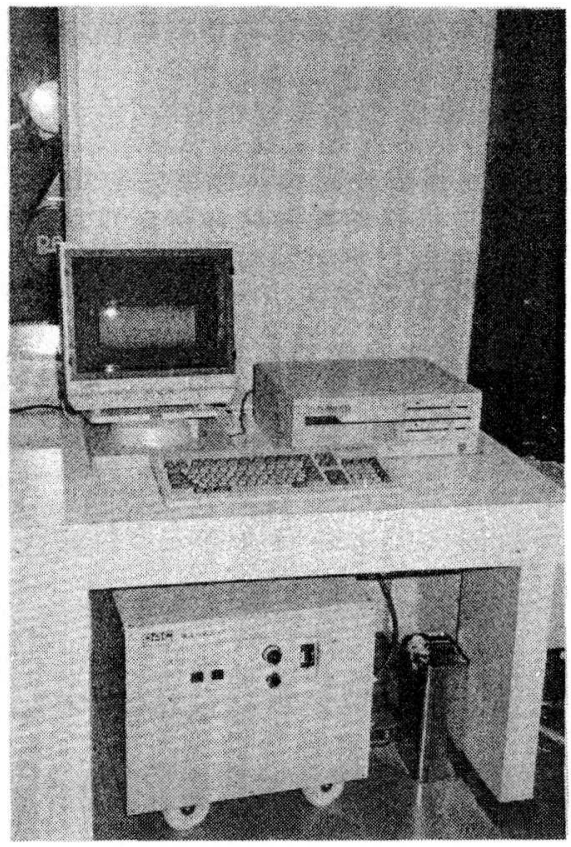

Photo.2 Operation Part 